Rand, Jane ORCID:

https://orcid.org/0000-0002-2314-6761 (2017) Misunderstandings and mismatches: the collective disillusionment of written summative assessment feedback. Research in Education, 96 (1). pp. 33-48.

Downloaded from: http://ray.yorksj.ac.uk/id/eprint/2113/

The version presented here may differ from the published version or version of record. If you intend to cite from the work you are advised to consult the publisher's version: http://journals.sagepub.com/doi/full/10.1177/0034523717697519

Research at York St John (RaY) is an institutional repository. It supports the principles of open access by making the research outputs of the University available in digital form. Copyright of the items stored in RaY reside with the authors and/or other copyright owners. Users may access full text items free of charge, and may download a copy for private study or non-commercial research. For further reuse terms, see licence terms governing individual outputs. Institutional Repository Policy Statement

\title{
RaY
}

Research at the University of York St John

For more information please contact RaY at ray@yorksj.ac.uk 
Misunderstandings and mismatches: The collective disillusionment of written summative assessment feedback.

Jane Rand

York St John University, UK.

j.rand@yorksj.ac.uk 


\section{Misunderstandings and mismatches: The collective disillusionment of written summative assessment feedback.}

Feedback is slippery, its meaning changes according to the space(s) you occupy within the perceptual limits that define it; these can range from feedback perceived as correction, to feedback perceived as longitudinal developmental. This provocation focuses on written summative assessment feedback, a format that remains one of the most common practices within academic programmes, that has the potential to be one of the most powerful influences on student growth, development and learning, and yet which many students report never reading. I develop the argument that written summative assessment feedback is the subject of collective disillusionment - the result of students misunderstanding assessment feedback discourses, and the mismatch(es) between student interpretations and lecturers' intentions of feedback. As provocateur, I argue that collective disillusionment not only risks the negation of written feedback, it seriously threatens learning. I draw upon empirical data to illuminate how paying attention to the kind(s) of work the representation of feedback does can contribute to feedback being re-framed for participation, and offer an open invitation for further dialogue via Research in Education.

\section{Keywords}

written feedback, summative assessment, collective disillusionment, affect 
Feedback is 'slippery’ (Boud and Molloy, 2013a: 5). Ranging in purpose from correction to longitudinal development (Price et al., 2010), it is often associated with (simplified) dualisms, for example formative and summative, tutor- and peer-, written and verbal; and although dualisms are often unhelpful, ‘interpretive dualism', Soja’s (1996: 5) principle of describing perceptual limits (or the points beyond which things no longer exist), can help to make 'practical and theoretical sense’ of feedback as a concept. The space(s) within these perceptual limits of feedback are slippery because the meaning of feedback changes according to the space(s) you occupy: learner, teacher, external examiner, quality assurer to name a few. The danger with dualisms is that they permit one side to be valued over the other (Pile, 1994) because they disguise differences within the binary limits. Feedback, however, can be perceived between what Carless (2015) refers to as ‘old paradigm' thinking: 'any of the numerous procedures that are used to tell a learner if an instructional response is right or wrong' (Kulhavy, 1997: 211), and contemporary thinking: as ‘a process in which students engage with feedback from various sources and make use of it to improve their work and/or develop their learning (Carless, 2015: 192). This, contemporary paradigm, moves from 'telling' to

... [a] process whereby learners obtain information about their work [from a variety of sources, including but not limited to teachers] in order to appreciate the similarities and differences between the appropriate standards for any given work, 
and the qualities of the work itself, in order to generate improved work. (Boud and Molloy, 2013a: 6)

Much has been written in higher education about feedback. It is considered: essential to learning, and about growth; enabling; central to building expertise; a complex and unique form of communication geared towards eliciting and using information about performance or understanding for improvement; deeply emotional; often misunderstood; and asymmetrical in power relations (Ashwin, 2015; Sadler, 2010; Hounsell, 2008; Rae and Cochrane, 2008; Hattie and Temperley, 2007; Carless, 2006; Taras, 2006; Weaver, 2006; Higgins, Hartley and Skelton, 2001).

Themes common within contemporary research around students’ reported dissatisfaction with feedback include that: it is too general, or vague; it lacks guidance (or includes no suggestions for improvement); it focuses on the negative, is often not clear, and is unrelated to assessment criteria (Rae and Cochrane, 2008; Weaver, 2006; Higgins, Hartley and Skelton, 2001). Yet, on the other hand, neophyte (and sometimes, not-so-neophyte) learners sometimes perceive that the presence of feedback, in an of itself, is sufficient to bring about improved performance (O’Donovan, Rust and Price, 2015; Beard, Humberstone and Clayton, 2014), even though many students report never reading the [written] feedback that they receive (Weaver, 2006). Theoretically, feedback is considered as one of the most powerful influences on student growth, development, learning and achievement (Rae and Cochrane, 2008); in practice it has become 
contested and multiperspectival in increasing measure, in parallel with the massification of higher education.

This paper focuses specifically on written feedback: 'information about student performance conveyed by prose' (Jolly and Boud, 2013: 105) on assessment at the end of a unit of study (summative assessment). I develop Hounsell’s argument (2008: 2) around 'collective disillusionment' in feedback: the result(s) of students misunderstanding assessment feedback discourses, or finding them largely inaccessible (Carless, 2006; Weaver, 2006; Higgins, Hartley and Skelton, 2001), and the mismatches between student interpretations and lecturers' intentions of feedback (Sopina and McNeill, 2015; Rae and Cochrane, 2008; Weaver, 2006). Collective disillusionment in feedback risks, in Bordieu’s (1984, 2010) terms, refusals and negations and ultimately therefore elimination; yet feedback is simultaneously positioned as one of the most powerful single influences on learning.

This paper is offered as a provocation, a means to initiate the dialogue of educational criticism - the discursive new specialization championed by Leonardo (2016) in the previous issue of Research in Education ... positioning myself (the intellectual) as novice: asking questions of feedback as a truth that never arrives and opening up a conversation about what kind of work the representation of feedback does (Leonardo, 2016). 


\section{Written (summative) feedback}

Written (summative) feedback is still one of the most common practices in academic programmes. It originated within, but is now largely detached from, a supportive and formative (Oxford/Cambridge tutorial) learning support system, positioned alongside one-to-one discussion and opportunities for (re-)drafting (Nicol, 2010). Within contemporary discourse it is understood as:

... information given [often] using pre-designed rating schedules, forms or 'score sheets' that might contain a tick in a box against a particular criterion or characteristic to indicate whether the work being assessed has that attribute. (Jolly and Boud, 2013: 105).

Contemporary written summative feedback is expected to replace historic practices based on teacher-student discussion, within a 'capsule' model of teaching (McCardle-Clinton, 2008: 95); and (so) '...carry the burden of being the primary instrument for improvement' (Sadler, 2010: 541; Nicol, 2010). O’Donovan, Rust and Price (2015: 9; emphasis added) identify that institutions who are 'brave enough to adopt evidence-based and theoretically sound approaches to assessment feedback' are 'likely to gain the most in an era when student satisfaction has become increasingly important'. This is an era of massification and marketization and, I argue, of misunderstanding(s) and mismatch(es). 


\section{Assessment feedback discourses in context: massification, marketisation, misunderstandings and mismatches}

The impact of massification (understood as the term that refers to $15-40 \%$ of an eligible population participating in Higher Education) is problematic. The postmodern ideology that shapes education as an industry is in tension, subject to what Berlant (2011) defies as ‘cruel optimism', because it is founded on, and dominated by an academy geared towards human development, thrust into a system that is geared towards student enrolment and income generation (Barnett, 1997: 6; McCardle-Clinton, 2008). For academics, a massified and marketised higher education system, predicated on the shift to a consumer-society, results in 'inadequate notions of the process and point of higher education’ (Barnett, 1997: 163), where education has become ‘encapsulated', like a ready-meal, and ‘packaged for easy consumption’ (McCardleClinton, 2008: 95). Rather than being developmental, 'capsule education’ is formulaic, and based on a confinement pedagogy, where education is treated like a 'reified and measurable product’ (McCardle-Clinton, 2008: 99).

The contours of the higher education system have been 'reconfigured over the last quarter-century' as modularised and performative (Hounsell, 2008: 8); this risks the quality of student learning. Massification of HE has resulted in a narrow framework of learning, and one which is typically less-iterative than historically (Nicol, 2010; Rae and Cochrane, 2008; Taras, 2006). 
The economies of scale in capsule education teaching practice have not been replicated in assessment practice (Glover and Brown, 2006). Modularisation has resulted in decreased opportunities for guidance, interaction, practice, and students’ development of systematic knowledge of their performance (Boud and Molloy, 2013b; Hounsell, 2008). Knowledge and feedback is piecemeal in nature (Glover and Brown, 2006), and there are reduced opportunities to carry forward learning from one module to another (Yorke, 2001). [Rust suggested a solution to this over a decade ago, in his own terms 'radical' (2000, 127): to disaggregate summative assessment from modules; treating modules instead as formative, and connecting summative assessment to programme learning outcomes only].

The representation of feedback.

Recognising that students are dissatisfied with feedback is one thing (and arguably part of a wider discussion, outside of the scope of this paper, around the problematic nature of measuring satisfaction in the context of higher education). Exploring why this might be is valuable; exploring why findings from current research resonate with literature on feedback from a decade ago, even more so. I return, then, to the conversation about what kind of work the representation of feedback does (Leonardo, 2016).

Assessment feedback discourses are largely misunderstood, or at least not fully accessible to learners (Carless, 2006; Weaver, 2006; Higgins, Hartley and Skelton, 
2001). Students need advice on understanding and using feedback, including its tacit assumptions, in order both to develop the capacity to engage with it and learn from it (Hounsell, 2008; Carless, 2006; Weaver, 2006) and to avoid feedback becoming a barrier that 'distort[s] the potential for learning' (Carless, 2006, 220).

Research indicates that student interpretations, and lecturers’ intentions, of feedback are often mismatched (Sopina and McNeill, 2015; Rae and Cochrane, 2008; Weaver, 2006). Students and lecturers are likely to conceptualise feedback in dramatically different ways (Higgins, Hartley and Skelton, 2001), resulting in a disparity between the perceptions of the nature of feedback and the use to which it is put (Glover and Brown, 2006):

\footnotetext{
Student disenchantment mounts when the feedback they get on their undergraduate work is too sparsely uninformative, or unconstructive, or comes too late to be of much practical use. Their faith it its value to them as learners therefore begins to wane. At the same time, staff who are already hard-pressed to mark and comment systematically on assignments and assessments find growing indications of students not taking feedback seriously, alongside diminishing evidence that their feedback has 'made a difference' to the quality of the work students produce (Hounsell, 2003)...[S]taff commitment to providing helpful feedback can therefore become increasingly undermined. (Hounsell, 2007: 102-3)
}

This explains, perhaps, why feedback can become a barrier that distorts the potential for learning (Carless, 2006: 220), but significantly it also positions feedback as the subject of 'collective disillusionment' (Hounsell, 2008: 2; emphasis added). This is problematic 
because collective disillusionment in feedback - one of the most powerful single influences on student growth, development, learning and achievement - could result in disaffection towards it (Ahmed, 2014) or, in Bordieu's terms in refusals and negations (1984, 2010), and ultimately therefore in elimination.

Contemporary written feedback operates in a transmission mode (Rae and Cochrane, 2008), symptomatic of a less-iterative system characterised by 'impoverished dialogue' (Nicol, 2010: 501). It is expected to '...carry the burden of being the primary instrument for improvement' and to replace historic practice based on teacher-student discussion (Sadler, 2010: 541; Nicol, 2010). Meanwhile research suggests that the modelling and interaction that takes place in classes and supervision, and the investment of others in the learning context has a stronger influence (Johnston et al., 2012; Rae and Cochrane, 2008).

Here is the tension again. If feedback (understood in broad principle as being information used by students as a basis for improving learning) is dominated by misunderstandings and mismatches, collective disillusionment looms large. Written feedback within a contemporary (mass) higher education framework is at risk of refusal and negation, whilst simultaneously being positioned as one of the most powerful single influences on learning. Learning, then is seriously threatened and urgent change is required. 


\section{What kind of work does the representation of feedback do?}

To illustrate my concern(s) about what kind of work the representation of feedback does (Leonardo, 2016), this paper draws on empirical data from a small scale study involving students engaged in a modularised undergraduate social science programme in a British University. The study adopted a partnership-based model in which a student-researcher was positioned within a research team of which I was also a member. As such, I argue that what was asked throughout the study, what was heard, and our interpretation(s) of what was said, made for more authentic outcomes than traditional student engagement within feedback studies that typically position students mainly as respondents.

Engaging students within the design, conduct and evaluation of research, and not just as participants, is central to improving our research, our practice, and our research practice. Considering whether such a partnership-based approach is 'brave' (O’Donovan, Rust and Price, 2015), whether it demonstrates courage in the face of danger is intriguing. Responses will differ according to the space(s) we occupy. Those spaces, to draw on another dualism, lie within the perceptual limits of what Nordensvärd (2011) identifies as ‘[T]he consumer metaphor versus the citizen metaphor'.

The empirical data shared within this paper were generated as part of an evaluation project in which an established summative assessment form (or 'front sheet') used within a small University Department was modified and piloted. The 
modifications we made arose from my academic colleagues' concerns to maintain, what we perceived as, high quality feedback (based on our own understandings of the role of feedback, on what we understood our students to value about our feedback style, and the opinions of trusted and valued peers such as External Examiners) in the context of the introduction of a University-wide ‘three-week turnaround' for summative assessment feedback.

The modifications to the feedback form (embedded within an electronic process of coursework submission and return of written feedback) comprised three key features:

(1) a section for feed-back (a summary evaluation of the extent to which the submitted work demonstrated the module learning outcomes) that could be either short and accompanied by in-text annotations, or more detailed but limited to the front-sheet;

(2) a section for feedforward (focussing on areas for improvement in future work) structured around three priority aspects for development. These sections preceded the (numeric) grade indicator, which (in the modified form) was followed by

(3) the physical highlighting of the University generic assessment criteria (a series of criteria differentiated by grade band) to provide a visual analysis of strengths and areas for development, geared towards helping students better appreciate the (numeric) fine-grading. 
The average turnaround time for feedback had been four weeks; these modifications were felt by academic colleagues to offer sufficient scope to meet the new turnaround time demand, and at the same time maintain high quality. Significant to the project was our ambition to model research-informed feedback practices, and to promote authentic student-centred evaluation of our proposed modifications.

\section{Considerations in the design and practice of the study}

The ambition for the project was to evaluate the piloted form through genuinely collaborative and partnership-based practice [support from the University’s Students as Researchers scheme was secured, which meant that a student could be employed as part of the research team]. The project began with the student-researcher (who studied in a different Faculty and who was not familiar with our feedback practice(s)), meeting with me to discuss the context of the research, to review examples of existing departmental feedback, and to review the design of the piloted feedback form. After this the studentresearcher (“EM”) led an initial review of the literature on assessment feedback, to familiarise herself with current research and practice.

Weaver's (2006) research, which explored whether written feedback demonstrated a student-centred approach to learning, was central to EM augmenting her personal understanding(s) and experience(s) of feedback within the framework of this small scale study. From this and other relevant studies (for example: Mags, 2014; 
McCann and Saunders, 2009; NUS, 2008; Carless, 2007; Glover and Brown, 2006) EM identified initial areas for investigation (Table 1).

Table 1 Initial themes identified for investigation by the student-researcher [insert here]

Discussion of these themes between EM and myself led to the identification of three broad objectives for exploration:

(1) How do students engage with (written) summative feedback? That is, how do students understand, approach and experience summative feedback?

(2) How comprehensive is students' understanding of the strengths and areas for development of their work as a result of the summative feedback?

(3) What do students do as a result of receiving summative feedback?

Focus groups, held in Semester Two, were chosen as an appropriate data-generation fora within which students were invited to reflect on written summative feedback on their Semester One coursework submissions. The focus groups were facilitated by EM, independently. They were audio-recorded (from which a transcript formed the basis of data analysis), and also included opportunities for students to contribute data by writing on post-it ${ }^{\mathrm{TM}}$ notes purposively in response to a specific ranking activity, and also as an additional and alternative means of contributing to the general discussion. 
A series of prompts for use within the focus group were created, following discussion between $E M$ and myself, as $E M$ had no previous experience of facilitating such a group discussion. In addition to supporting the exploration of students' experience(s) of their written summative feedback, the prompts were designed to enable students also to engage in dialogue around how they would evaluate, and make recommendations for improvement to, the (piloted) feedback form (Table 2).

\section{Table 2: Prompts for focus group discussions [insert here]}

The practice of the study was interpretive; it was an exploration of students' perceptions of the value of their (written) feedback, in terms of both content and format. An opportunistic approach was taken to identify programme(s) cohorts to be invited to participate in the study. In consultation with Departmental tutors, a decision was taken to limit invitations to those students in years one and two of full-time undergraduate study, as third year students were approaching submission deadlines for major projects. Thirty full-time students consented to participate in the research, representing four distinct programmes of study (approximately half of the Department’s programmes), with a ratio of first- to second-year student of approximately 1:2.

Five focus group meetings were held; EM transcribed the audio-recording for each and collated the post-it note ${ }^{\mathrm{TM}}$ data electronically. We met to review the full transcripts, discuss our initial reactions, ask questions of each other (for clarification 
and verification), consider emerging 'units of meaning' (Wellington, 2015) and discern themes for the basis of a deeper analysis. An academic colleague (new to the Department and not involved in the original re-design of the feedback form) joined these discussions, acting as a critical friend.

How do students understand, approach and experience (written) summative feedback?

What we heard about how students experience written feedback is well-rehearsed in the literature (see for example, Boud and Molloy, 2013; Carless, 2006, 2007; Glover and Brown, 2006; Hounsell, 2008; Weaver, 2006; Zimbardi et al. 2016). Overwhelmingly, students reported locating their grade (at the bottom of the form) before reading the written comments. Most students reviewed the written comments as a secondary activity, although many reported never reading the written comments, and often students reported delaying reading the comments particularly if they perceived the grade as 'bad'. Most students reported reading the comments only once. There was no explicit rationale for this, rather feedback appeared to be conceptualised as disposable or in some way 'single-use'. Some students reported reading the feedback only once because they felt it would have no relevance to subsequent modules.

Students described not understanding their feedback more often than understanding it, often reporting themselves as confused by: 
(1) vagueness:

on quite a lot of mine I got a lot of “reference errors”, but he didn't say what the errors were, so I kept making the same mistakes again and again...it wasn't saying on the feedback sheet exactly what they were, it wasn’t until recently that I asked a tutor what I'd done wrong, and he told me. It went through all of last year but because it wasn't very specific I couldn't change it.

Sometimes they just put ‘too vague' and you're like, “what do you actually want”? That's a bit vague! Maybe the comments need clarifying a bit.

(2) the use of terms that are unfamiliar, or perceived as unnecessarily specialised: ...they do like to use long words don’t they?

and

(3) inconsistencies:

...one lecturer might not like headings and one might. Like one lecturer might say “you’ve set out your report really well” and you might get another that says "no, this is not how I wanted it”...we’ve found everyone’s very different.

Students generally reported experiencing relief when they passed modules, and frustration when feedback was difficult to understand; and, although the (earlier) conceptualisation of 'single-use' or disposable feedback could be a reflection of a contemporary ‘throw away’ society or of deliberate surface approaches to learning 
(Nicol 2010), an alternative interpretation suggests the under-researched area of emotional investment in the receipt of feedback (Poulos and Mahony, 2008).

In her work on affect (responsive forces beyond emotion), Ahmed (2014) warns of the risk that affect can result in towardness or awayness in relation to its object(s), in this case: feedback. And Sadler (2010: 539) cautions writers of feedback to ensure they commit considerable 'affective outlay' to what is written, because of its asynchronous, typically monologic, nature. The nature of how feedback is experienced as affective and relational [if, then/so] was also evident in the data:

If I got a high grade I'd be in a good mood ...so I'd take time to read it

If you think you've done well...it can be a big deal when you get bad feedback.

Yeah if I got a low feedback grade I'd wanna read it but wait like a day to recover.

If I get a lower mark then I don't really read the feedback until the next day.

How comprehensive is students' understanding of the strengths and areas for development of their work as a result of the feedback?

Students described finding it hard to discern strengths or positive statements in the summary written feedback, resulting in misunderstandings particularly connected to inconsistencies between the summary and in-text comments: 
Sometimes it can be confusing, they'd write negative comments in the summary, but then it didn't really match up with the comments in text, they seemed quite okay....it wasn’t very helpful really...

Whilst the original intention for the feedback, and of the feedback form, was pluralist and complementary: areas for development (or ways in which to mature, advance or elaborate) were offered alongside a summary evaluation (geared towards constructive critique that would include identification of strengths, or positive features), the focus group dialogues suggested students held largely binary (positive/negative) perceptions of feedback: a mismatch.

Students expressed an explicit desire for positives, as approval, and in binary opposition to their perception of the disapproval of (constructive) criticism:

...I remember one that we did it was just all negatives...it would be nice to have a box where they could say you have done this and you've done this well...just to give you a bit of a boost really.

Maybe not put a negative at all because you're instantly criticising the work...maybe just have a box where they can say I really liked this, however maybe do this next time.

What do students do as a result of receiving written summative feedback? As noted above, overwhelmingly students identified that they located the grade before reading the summary narrative or in-text comments (if at all): 
Straight away I looked at the mark first then looked at the main comments, then afterwards I'd go through the whole thing.

Looked straight for the number.

Looked at the feedback after the number, but the number first.

Most reported taking no further specific action. Some described contacting tutors to request a more detailed dialogue, particularly when the grade was perceived as 'bad', and one student reported downloading (consecutive) feedback to their iPad ${ }^{\mathrm{TM}}$ and finding it useful to locate different feedback 'side by side’.

Whilst the three priority development points were generally considered to be helpful, this was largely because they were perceived as 'breaking down', or distilling, the summary narrative. From this distillation, one student reported a more detailed, analytic, autonomous response:

Yeah I looked at the mark first and re-read my assignment to see what had been highlighted as well, and anything annotated on there as well and tried to link that with the feedback sheet

And another articulated their recognition of the value, in principle, of explicit development foci; s/he described this value as questionable in practice, however, because of inconsistencies: 
I think it's a good idea, but not much point because lecturers are so different... some like headings, some HATE headings, some like speech marks, some hate them! [emphasis in original]

\section{Students' evaluation of the piloted form}

Students generally reported that the layout was helpful to them (information appears in the same place on the form for each module, 'regardless of the marker'), and they found the additional visual analysis (from highlighting the assessment criteria) useful to support their understanding of the grade awarded to their work.

Students were asked to consider the top-three characteristics that make any written feedback helpful to them, and identified:

(1) clear identification of ways to improve subsequent assessments;

(2) the inclusion of positive comments;

(3) accessibility/availability (an electronic format means that feedback is legible and could be 'saved for future use').

In evaluating the form against their own criteria most students felt that the piloted form did allow for criterion (1) and (2) and, as the form was used exclusively electronically, it was also unanimously considered to meet criterion (3). Criterion (2) is interesting insofar as it confirms the explicit distinction of 'positive' comments from the identification of 'strengths'; suggesting a preference for praise or approval alongside 
ways in which to improve, rather than an evaluative summary from which ways to improve might logically follow. This illuminates the affective fabric of education (Staunaes, 2016): students' emotional resilience appears in some way disabled by the format of the feedback. This is unsurprising perhaps when one reflects on students' earlier learning experience(s) and the influence of wider, contemporary, education practices:

There has been such a sweeping reform in school-based education to avoid criticism and comparison of students' performances, and the replacement has been praise. It is not surprising that learners, after transition into higher education or workplace-learning, feel ill-equipped to process information formulated for the purpose of improvement. For these learners, the psychological immune system is forced into overdrive as these individuals may have no orientation to, nor practice in, how to use these judgements for positive change. (Molloy, Borrel-Carrió, and Epstein, 2013: 61)

When asked what recommendations for improvement(s) to the form students would make, overwhelmingly they suggested relocating the grade from the bottom to the top of the form. Many also suggested an alteration in the balance between the summary narrative and the priority development areas, requesting less of the former and more of the latter; suggesting less opportunity to receive 'criticism' and more identification of what is necessary to 'put things right'. 
In some ways, these represent a form of psychological immunisation... a boost to emotional resilience... a preparatory shield to the call to arms of judgement, and the 'battle’ of (emotionally-laden) positive change.

\section{Impact?}

One small, but nonetheless significant, outcome was reported by students as being useful them in the follow-up year: the grade was repositioned to the top of the feedback form. In some senses this is 'brave’ (O’Donovan, Rust and Price, 2015); it is certainly controversial, and justified not through engagement with learning theory and the contemporary canon of literature on assessment feedback, but through attending to a local, contextualised, evidence-base and paying attention to the kind of work the (local) representation of feedback does.

It would be true to say that discussion with academic Departmental colleagues favoured removal of the grade from the form entirely, however, dialogue with $E M$ encouraged us to consider the risk that removal of the grade from the form might result in students 'seeking out' the grade (elsewhere) and disregarding the written comments entirely.

Four students remained involved in the research and were followed-up in their subsequent year of academic study through a short series of one-to-one dialogues within academic tutorials. They reported changed practices in their reading of written summative assessment feedback. In practice, as previously, each of the students 
reported that they continued to look at the (re-positioned) grade first, but each also reported reading the written comments at least twice; they reported mostly understanding the feedback, having a good sense of the strengths of the submitted work, and, with the exception of one student, having a good sense of how to further develop.

In this follow-up engagement with students they reported a more nuanced conceptualisation of 'positively-framed' comments making feedback helpful. This suggests a maturity that moves beyond seeking praise, towards constructive critique or 'encouragement coupled with suggestions on how to attend to specific deficiencies and strengthen the work as whole' (Sadler, 2010: 536). It suggests that reframing feedback for participation reduces the serious threat to learning. It suggests that the kind(s) of work the representation of feedback does, for these students, has changed.

... and all because the grade was relocated? Unlikely. But because students were able to say what they wanted to receive, and because lecturers were able to explain what they wanted to give ... and both representations were heard? More likely.

As researchers and intellectuals we have an ethical responsibility for 'systematic, critical and self-critical inquiry’ (Bassey, 1990: 35; emphasis added). Engaging with students in research and also engaging students within the design, conduct and evaluation of our research is central to improving our research, our practice(s), and our research practice(s). It is also a way in which genuine, 
contextualised, evidence-bases, from which 'theoretically sound approaches [to assessment feedback]' (O’Donovan, Rust and Price, 2015) can be adopted.

\section{Assuming the role of provocateur}

A provocation is a means to initiate the dialogue of educational criticism (Leonardo, 2016); it might also be considered as (en)couraging - a means of enacting strength in the face of danger.

There is a danger that learning is under serious threat. The kind(s) of work the representation of feedback does for students in a massified and marketised Higher Education system directly contributes to that threat.

\section{[leave extra line space here]}

A knowledge society operates a social epistemology (Barnett, 1997) in which learning means '... developments of worthwhile kinds, with some insight, that fosters purpose and that enables response, or conscious thinking' (Barnett, 1997: 159), and learning is understood to develop from 'process[es] in which students engage with feedback from various sources and make use of it to improve’ (Carless, 2015: 192). To develop worthwhile kinds of learning then, it follows that feedback must be perceived to be worthwhile.

Worth, or value, is subjective. 
If the subjects are students, we must appreciate that today's students are positioned (by policy) as consumers, in a market of universities-as-providers of products and services, and there has been '... a move from 'being' to 'having' [that] represents an intellectual shift ... with some students seeking satisfaction in the fulfilment of their rights as opposed to a struggle with theoretical content' (Williams, 2011: 172).

And if the subjects are students, and if assessment feedback is one of the most powerful single influences on (student) learning, then feedback integral to a social epistemology must foster purpose within students and be useful to students - it must be valuable. Yet Boud and Molloy (2013b: 699) warn that '[the] more recent regime of assessment may have arisen [because of massification and modularisation] at the expense of worthwhile learning opportunities'.

Feedback must be re-framed for participation. Mutually constructed and codependent feedback (Boud and Molloy, 2013) recognises, of course, that the subjects are not only students. Students and academics (and others) occupy the slippery spaces that define feedback.

Feedback re-framed for participation, with students as active agents in monitoring and evaluating their own learning, and where they engage with (and seek out) feedback from varied sources rather than 'receiving' it (from lecturers) alone (Boud and Molloy, 2013b; 711) is sustainable within a mass higher education system, but 
students rarely arrive at University equipped for this. There is a mismatch between what students want to receive and what lecturers want to give (Tapp, 2015); collective disillusionment perpetuates.

Any development of worth to its subjects exists outside of disillusionment. It exists where those involved have confidence in it, and are convinced by it. For students and academics (and others) to have confidence in, and be convinced by feedback, there needs to be a mutual understanding of its nature and purpose, this requires a mutual exploration of the slippery spaces that define it.

Collective disillusionment in feedback cannot exist in the same way if students and academics share the spaces that define feedback. Disillusionment can be reduced through shared research into feedback, where the tail of policy-drivers is interrupted (at least) in its attempt(s) to wag the learning dog. But this will require new, brave, approaches, ‘...likely to involve fundamental changes to rules, processes and resource allocations' (O’Donovan, Rust and Price, 2015: 946). These fundamental changes include (local) evidence-based approaches. More significantly, in order to be authentic, I argue that they must also include a commitment to design and interpret the exploration of the evidence-bases themselves from a shared occupation of the spaces that define feedback. Only then can we (begin to) know the kind(s) of work the representation of feedback does. 


\section{Acknowledgements}

The author would like to thank the students, whose voices are reflected in this paper, and in particular EM for commitment, enthusiasm, curiosity, purpose, eagerness to learn and willingness to teach.

\section{Declaration of conflicting interests}

The author declared no potential conflicts of interest with respect to the research, authorship, and/or publication of this article.

\section{Funding}

The author received no financial support for the research, authorship, and/or publication of this article. 


\section{References}

Ahmed S (2014) The Cultural Politics of Emotion. $2^{\text {nd }}$ ed. Edinburgh: Edinburgh University Press.

Ashwin P (2015) Reflective Teaching in Higher Education. London: Bloomsbury Academic.

Barnett R (1997) Higher Education: A Critical Business. Buckingham: SRHE and Open University Press.

Bassey M (1990) On the Nature of Research in Education (Part I). Research Intelligence 36 (Summer): 35-38.

Beard C, Humberstone B and Clayton B (2014) Positive emotions: passionate scholarship and student transformation. Teaching in Higher Education 19(6): 630-643.

Berlant L (2011) Cruel Optimism. Durham and London: Duke University Press.

Boud D and Molloy E (eds) (2013a) Feedback in Higher and Professional Education. Understanding it and doing it well. Abingdon: Routledge.

Boud D and Molloy E (2013b). Rethinking models of feedback for learning: the challenge of design. Assessment \& Evaluation in Higher Education 38(6): 698712.

Bourdieu P (1984, 2010) A Social Critique of the Judgement of Taste. Translated by Richard Nice. Translation published in 1984 by Routledge + Kegan Paul, PLC. First published by Routledge Classics 2010. Oxon: Routledge.

Carless D (2015) Excellence in University Assessment. Learning from award-winning practice. Abingdon: Routledge.

Carless D (2006) Differing perceptions in the feedback process. Studies in Higher Education 31(2): 219-233. 
Carless D (2007) Learning-oriented assessment: conceptual bases and practical implications. Innovations in Education and Teaching International 44(1): 57-66.

Glover C and Brown E (2006) Written Feedback for Students: too much, to detailed or too incomprehensive to be effective? Bioscience Education 7 (May) https://www.heacademy.ac.uk/written-feedback-students-too-much-too-detailedor-too-incomprehensible-be-effective

Hattie J and Timperley H (2007) The Power of Feedback. Review of Educational Research 77(1): 81-112.

Higgins R, Hartley P and Skelton A (2001) Getting the Message Across: the problem of communicating assessment feedback. Teaching in Higher Education 6(2): 269274.

Higgins R, Hartley P and Skelton A (2002) The Conscientious Consumer: Reconsidering the Role of Assessment Feedback in Student Learning. Studies in Higher Education 27(1):53-64.

Hounsell D (2007) Towards more sustainable feedback to students. In: Boud D and Falchikov N (eds) Rethinking Assessment in Higher Education. Learning for the Longer Term. London: Routledge, pp.101-113.

Hounsell D (2008) The Trouble with Feedback. New Challenges, Emerging Strategies. TLA Interchange 2:1-9.

Johnston B, Mitchell R, Myles F and Ford P (2012) Developing Student Criticality in Higher Education. Undergraduate Learning in the Arts and Social Sciences. London: Bloomsbury Academic.

Jolly B and Boud D (2013) Written feedback. What is it good for and how can we do it well? In: Boud D and Molloy E (eds) Feedback in Higher and Professional education. Understanding and doing it well. Abingdon: Routledge, pp. 104124. 
Kulhavy RW (1977) Feedback in written instruction. Review of Educational Research 47(1): 211-32.

Leonardo Z (2016) Educational criticism as a new specialization. Research in Education. Prepublished October 2016. DOI:10.1177/0034523716664604.

Maggs L (2014) A case study of staff and student satisfaction with assessment feedback at a small specialised higher education institution. Journal of Further and Higher Education 38(1): 1-18.

McCann L and Saunders G (2009) Exploring student perceptions of assessment feedback. SWAP Report. York: HEA.

McCardle-Clinton D (2008) The Consumer Experience of Higher Education. The Rise of Capsule Education. London: Continuum.

Molloy E, Borrell-Carrió F and Epstein R (2013) The impact of emotions in feedback. In: Boud D and Molloy E (eds) Feedback in Higher and Professional education. Understanding and doing it well. Abingdon: Routledge, pp.50-71.

Nicol D (2010) From monologue to dialogue: improving written feedback processes in mass higher education. Assessment \& Evaluation in Higher Education 35(5): 501-517.

Nordensvärd J (2011) The consumer metaphor versus the citizen metaphor: different sets of roles for students. In: Molesworth M, Scullion R and Nixon E (eds) The Marketisation of Higher Education and the Student as Consumer. Abingdon: Routledge, pp. 157-169.

NUS (2008) NUS Student Experience Report. London: NUS.

O’Donovan B, Rust C Price M (2015) A scholarly approach to solving the feedback dilemma in practice. Assessment \& Evaluation in Higher Education 41(6): 938949.

Pile S (1994) Masculinism, the use of dualistic epistemologies and third spaces. Antipode 26(3): 355-277. 
Poulos A and Mahony MJ (2008) Effectiveness of feedback: the students' perspective. Assessment \& Evaluation in Higher Education 33 (2):143-154.

Price M, Handley K, Millar J and O’Donovan B (2010) Feedback: all that effort, but what is the effect? Assessment \& Evaluation in Higher Education 35 (3):277289.

Rae AM and Cochrane DK (2008) Listening to students. How to make written assessment feedback useful. Active Learning in Higher Education 9 (3):217-230.

Rust C (2000) An opinion piece. A possible student-centred assessment solution to some of the current problems of modular degree programmes. Active learning in higher education 1 (2):126-131.

Sadler DR (2010) Beyond feedback: developing student capability in complex appraisal. Assessment \& Evaluation in Higher Education 35 (5):535 - 550.

Soja EW (1996) Thirdspace. Oxford, England: Blackwell Publishing.

Sopina E and McNeill R (2015) Investigating the relationship between quality, format and delivery of feedback for written assignments in higher education. Assessment \& Evaluation in Higher Education 40 (5):666-680.

Staunaes D (2016) Notes on inventive methodologies and affirmative critiques of an affective edu-future. Research in Education. Prepublished October 2016. DOI: $10.1177 / 0034523716664580$.

Tapp J (2015) Framing the curriculum for participation: a Bernsteinian perspective on academic literacies. Teaching in Higher Education 20 (7):711-722.

Taras M (2006). Do unto others or not: equity in feedback for undergraduates. Assessment \& Evaluation in Higher Education 31 (3):365-377.

Weaver MR (2006) Do students value feedback? Student perceptions of tutors’ written responses. Assessment \& Evaluation in Higher Education 31 (3):379-394.

Wellington J (2015) Educational Research. Contemporary Issues and Practical Approaches. $2^{\text {nd }}$ ed. London: Bloomsbury. 
Williams J (2011) Constructing consumption: what media representations reveal about today’s students. In: Molesworth M, Scullion R and Nixon E (eds) The Marketisation of Higher Education and the Student as Consumer. Abingdon: Routledge, pp. 170-182.

Yorke M (2001) Formative assessment and its relevance to retention. Higher Education Research and Development 20 (2):115-126.

Zimbardi K, Colthorpe K and Dekker A (2016) Are they using my feedback? The extent of students' feedback use has a large impact on subsequent academic performance. Assessment and Evaluation in Higher Education. Epub ahead of print 19 May 2016. DOI: 10.1080/02602938.2016.1174187. 


\section{TABLES}

Table 1 Initial themes identified for investigation by the student-researcher

- Time spent reading written feedback

- The extent to which students feel they understand written feedback

- The extent to which students are 'satisfied' with the quality of written feedback they receive

- The extent to which student believe written feedback helps them improve future assignments

- What students perceive as 'helpful' and 'unhelpful' feedback

- Changes students perceive would be appropriate to written feedback in order to help them improve their work

Table 2: Prompts for focus group discussions

\begin{tabular}{|c|c|}
\hline \multirow{7}{*}{$\begin{array}{l}\text { Focussing on } \\
\text { Semester } 1 \\
\text { modules' feedback }\end{array}$} & $\begin{array}{l}\text { How did students read the feedback, and how often,... what } \\
\text { process/es did you follow, were these the same for each module? }\end{array}$ \\
\hline & How did students feel when reading the feedback? \\
\hline & $\begin{array}{l}\text { Did students feel that they generally understood the written } \\
\text { feedback...examples...examples of things not understood? }\end{array}$ \\
\hline & What did students feel about the depth/detail of the feedback? \\
\hline & $\begin{array}{l}\text { Did students feel that the strengths of their work were identified } \\
\text { in the feedback...examples? }\end{array}$ \\
\hline & $\begin{array}{l}\text { What did students do as a result of receiving the feedback...was } \\
\text { this the same for each module? }\end{array}$ \\
\hline & $\begin{array}{l}\text { Did students find the Semester } 1 \text { feedback helped them to } \\
\text { improve their work/approach to work in Semester } 2 \text { ? }\end{array}$ \\
\hline \multirow{4}{*}{$\begin{array}{l}\text { Focussing on the } \\
\text { (new) feedback } \\
\text { form }\end{array}$} & $\begin{array}{l}\text { [How] Did students find the three areas to develop section } \\
\text { useful? }\end{array}$ \\
\hline & What do students find helpful and unhelpful in the new form? \\
\hline & $\begin{array}{l}\text { What development points would students suggest for the new } \\
\text { form? }\end{array}$ \\
\hline & $\begin{array}{l}\text { What do students think are the top three things that make written } \\
\text { feedback helpful? } \\
\text { Based on those three things, how would students score the new } \\
\text { form }(3,2,1 \text { or } 0) \text { ? }\end{array}$ \\
\hline
\end{tabular}


